ISSN: 2162-3104 Print / ISSN: 2166-3750 Online Volume 6, Issue 3 (2016), pp. 712-721 (C) Journal of International Students http://jistudents.org/

\title{
Comparing International and American Students' Challenges: A Literature Review
}

\author{
Cody J. Perry \\ University of Wyoming, USA
}

\begin{abstract}
International student numbers have increased drastically in the past few years. International students provide benefits to universities and American students such as greater revenue, and more open-mindedness. There have been myriad studies that have examined the international student experience, but most have focused solely on international students. However, a careful examination of the current literature demonstrates that the presence of international students in the United States offers a variety of benefits to American students by improving cultural awareness, students' self-evaluated skills, and even the American economy. This literature review highlights future research that should be performed as well as strategies that can be implemented by faculty and administration to help international students who are currently studying in the United States.
\end{abstract}

Keywords: International education, comparative education, improving international perceptions

The number of international students grew to approximately 862,000 students for the 2013-2014 academic year and accounted for nearly \$27 billion in economic spending (Witherell \& Clayton, 2014). These students offer a variety of benefits to others as they improve cultural awareness, American students' self-evaluation of skills and abilities, and provide additional foreign funds to the American economy (Luo \& Jamieson-Drake, 2013). Incoming students such as freshmen, international students, and first-generation graduate students often struggle with the transition to academic life as it differs from the processes they have experienced in the past (de Araujo, 2011; Gardner, 2013). By examining these students and the transitions that take place in academic settings, researchers can identify issues and obstacles that students may face as well as those items that may 
cross cultural and national boundaries. While international and domestic students have many differences, comparison of the two groups reveals that many struggles are shared by the two. This would indicate that interventions and practices that work for one group may be adapted to the benefit of the other group. The existing literature on these different student groups provide educators and administrators information that can be utilized to improve the education that colleges and universities offer.

International students are an expanding segment of the student population in the United States, accounting for $4 \%$ of all students (Witherell \& Clayton, 2014). These students must deal with a variety of difficulties such as language barriers, acclimating to a new culture, and different cultural philosophies and approaches to curricula (Sherry, Thomas, \& Chui, 2010). However, American freshman and first generation students often deal with issues as they make the transition to a new life and location. This literature review attempts to find the similarities and differences between these groups as well as underlying themes that can improve education for all post-secondary students studying in the United States.

The search for this literature review was conducted using the university's online research database, with articles being restricted to publication within the previous ten years. However, when consulting the most recent articles, many referenced articles older than 10 years. A few of these articles were also included based on their influence and multiple citations in the current research literature. The search was limited to articles that had been peer-reviewed and were available for online reading. Documents from all nations were considered in the study, however most utilized were performed at institutions in the United States. Search terms used in the search included international student issues, challenges, and obstacles; comparing international and domestic students; and issues in comparative education.

\section{FINDINGS FROM THE LITERATURE}

Similarities. International and domestic students have many apparent differences, but their similarities may help colleges and universities tailor their programs to better meet the needs of multiple groups. Both international and American students reported similar levels of satisfaction with the university experience (Grayson, 2008). However, due to adjustment to new surroundings, many students dealt with issues that may have created mental and emotional issues. For instance, first year American students, international students, and first generation doctoral students all reported feelings of alienation or separation as a result of their new surroundings (Burdett \& Crossman, 2012; Gardner, 2013). Also, according to data on counseling and social interaction, American and international 
students differ in some areas, but not in many important aspects of the research. For example, neither group showed significant differences in the importance of their social experiences (Curtin, Stewart, \& Ostrove, 2013). Additionally, first year domestic students and international students both dealt with emotional issues such as anxiety and depression (Mitchell, Greenwood, \& Guglielmi, 2007; Rodgers \& Tennison, 2009). Both groups' most prolific concern in regards to mental health was relationship problems, though international students were more concerned with relationships with faculty than American students (Hwang, Bennett, \& Beauchemin, 2014). Therefore, international and American students, though different in many aspects, suffer from many of the same emotional difficulties regardless of their place of origin.

In addition to emotional and mental health issues, both international and American students often struggle with their academic pursuits. Grayson (2008) found that $74 \%$ of international students had issues with studying, while $65 \%$ of domestic students reported the same issue. Moreover, both groups of students had similar views on advisor support and their relationship with their advisors and professors (Curtin et al., 2013). More importantly, students showed a positive correlation between support received from their advisor and their academic self-concept (Curtin et al., 2013). This may indicate that students who had a positive working relationship with their advisor felt better equipped to perform their academic duties. However, until a causal relationship is determined, one can only speculate at the connection.

Related to advisor support is the use and acceptance of advice from others while pursuing a degree. In a study of advice perceptions, both American and Chinese students found advice that was feasible and effective to be more valuable (Feng \& Feng, 2013). However, Chinese students preferred to receive their advice from someone who was perceived to be an expert, whereas American students placed more emphasis on the content of the advice itself. This may indicate that relationships are more important to students from collectivist cultures than those from individualistic societies. All of these similarities indicate that international and domestic students can both benefit from previous and future research concerning the university experience.

Unique challenges for international students. Although there are many issues and obstacles that international students share with their American peers, there are also numerous challenges that are unique to the international student experience. Unfamiliar campuses and the novelty of a new nation can be overwhelming and give one a sense of alienation (Burdett \& Crossman, 2012). In fact, many students felt left out (Sherry et al., 2010), and stated that they preferred to make friends with people of their 
own nationality or from a similar background (Zhao, Kuh, \& Carini, 2005). However, Grayson (2008) found that international students were more involved in school groups and clubs than their American peers. This may be due to the fact that many clubs and groups are organized based on religious or ethnic backgrounds. These groups allow international students to find people who have similar interests, beliefs, and backgrounds, but may prevent socialization with people of diverse backgrounds. International students also struggle with making friendships and getting academic help from their peers (Grayson, 2008). This may be due to Curtin's (2013) findings that many international students placed more emphasis on research and professional development than American students. Therefore, international students who desire to make more social connections may be hampered by the demographics of the groups available to them and their concentrated focus on academic pursuits.

Language differences contribute to socialization and friendship issues, but it also plays a role in other challenges that international students may have to overcome. For example, students who reported lower levels of English skills also reported higher levels of discrimination (Poyrazli \& Lopez, 2007). Discrimination is an issue that still seems to be prevalent on many American campuses and continues to be a problem for many international students. As many as $50 \%$ of international students have stated they have dealt with discrimination in some form or another (2007). Language can be troublesome in other areas as well and is not restricted to feelings of discrimination and social acceptance.

Academics and language are also closely connected, with many students struggling after passing their English language exams before coming to study in the United States (Burdett \& Crossman, 2012). Language differences led many students to feel anxious when speaking in front of Americans, which may hamper their desire to share their thoughts and opinions in the classroom (Lin \& Scherz, 2014). Asian students seemed to struggle most with language issues as many had difficulty in understanding lectures from American professors (2014). However, some interventions have helped to alleviate some of the issues that have arisen. One well-received intervention is the use of online language support for students (Burdett \& Crossman, 2012). Since many students feel anxious when speaking to Americans, the use of online aids may allow international students to retain their dignity while also receiving the language support that they need.

The language barrier is often a difficult issue to overcome, but international students also deal with diverse emotional issues that may affect their overall perceptions of their experience in the United States. Students with low English skills reported higher levels of homesickness, which led to more complaints of physical issues, anxiety, and forgetfulness (Poyrazli \& 
Lopez, 2007). Moreover, Asian students were more distressed than North American and European students who were studying in the United States (Mitchell et al., 2007). This study also found that, although all students had similar issues, international students were more likely to be hospitalized for their mental health issues. This is an issue that can make life in a foreign country even more difficult, especially when one considers that the social needs of international students are not necessarily being met.

Lastly, international students deal with issues that are present in the American education system that may be taken for granted by domestic students. One such is the use and implementation of technology. While most international students used technology in their studies, many struggled with it (Habib, Johannesen, \& Øgrim, 2014). The online courses and learning modules were not intuitive to many students, and they struggled when told to simply log onto the student online portal (2014). As stated previously, online language support was found to be helpful, but many facets of the online experience can be problematic for international students.

International and domestic students encounter many difficulties when they begin their post-secondary education. Some of these challenges are faced by a variety of groups including freshman, international students, and first generation graduate students. However, international students have many unique challenges and obstacles and may not have a support system similar to that of many domestic students. Yet, many international students enjoy their time in the United States and those who persist often have little difference in perception by their final year (Rodgers \& Tennison, 2009). From the literature, many positive lessons can be learned and implemented in American institutions to benefit students from numerous backgrounds.

Synthesis. There are many benefits that can be derived from a study of the current literature comparing the challenges of American and international students in post-secondary institutions. First, increased advisor visibility and support can benefit numerous students in the United States. Although Grayson (2008) found that international students were less involved in the classroom than their peers, they often had more study time and more contact with faculty outside of the classroom. With the increased demand of international study, these students may need more contact from their faculty advisors in order to navigate some of the novel changes they will experience. In addition, American students who reported more contact with faculty were found to have more interaction with international students, leading to better self-concept and self-assessment of skills (Luo \& Jamieson-Drake, 2013). Therefore, increased advisor presence can benefit both international and domestic students, though this may also put a greater strain on faculty members' already strenuous workload. 
Research provides specific suggestions for the faculty member to improve the international student's experience. First, in advising meetings, professors should give careful consideration to the advice they provide to their students, especially if they are from a collectivist culture (Feng \& Feng, 2013). Since many of these students place more emphasis on the relational ties to the advice given, it is important to have a good relationship with the student before offering advice. Secondly, instructors should simplify their language and define difficult terms, especially if they are culturally specific (Lin \& Scherz, 2014). By doing so, international students may feel less confused and add more to the conversation, giving domestic students more diverse viewpoints in the classroom. In addition, professors may choose to include some non-text assignments, like video presentations, to aid those students who struggle with the English language (Habib et al., 2014). By adding these options to courses, international students may be able to participate more fully and visual learners may benefit as well. Finally, international students have stated that they would like to see more detailed and specific assignment expectations (Lin \& Scherz, 2014). By explicitly stating the requirements for a course or assignment, professors will also decrease errors in domestic students' assignments while also helping international students' understanding.

Advisor support is helpful and necessary for the success of all postsecondary students; yet international students' interactions outside of the classroom are important to future success as well. While social interaction is important to all students, it is important to note a few distinctions. First, international students who had made friends with Americans were better able to adjust and adapt to their new surroundings (Zhao et al., 2005). Additionally, students who had integrated well and had high levels of English proficiency reported lower levels of discrimination (Poyrazli \& Lopez, 2007). Therefore, it is important to understand that helping students with their language skills is important for a variety of reasons. In contrast, too much socialization may have an adverse effect. International students with very high social integration were less likely to persist in their studies (Mamiseishvili, 2012). Moreover, American students who were involved in sororities or fraternities were less likely to interact with international students and missed out on the possible benefits of such relationships (Luo \& Jamieson-Drake, 2013). Thus, it is important to help students acclimate to their new surroundings without creating students who neglect their studies and the opportunities that they have been offered.

The current research offers solutions that can help students to socialize properly, improve their language skills, and improve their mental health. As many international students already underutilize university services, it is important to give students a supportive environment from the beginning to avoid some of the mental health issues that may arise (Zhai, 
2000). Before students arrive in the United States, institutions should have a person from a similar background contact the student in their home nation (Telbis, Helgeson, \& Kingsbury, 2014). This will allow new students to ask questions from someone whom they may view as an ally and provides them with a contact person before they enter the United States. Once students have arrived, Telbis (2014) suggests a peer program to match an American student with a new international student. This will allow the student to get information about services in the area, differences in culture, etc. from an American student who can help them acclimate to their new environment.

Since academics are very important to many international students, mentoring or partnering approaches should be incorporated in addition to the partner programs listed above (Korobova \& Starobin, 2015). Although many universities set up ethnic and religious based groups, it may be helpful to form study groups that will allow for diverse interactions outside of the classroom (Mamiseishvili, 2012). Since many Asian students are more reluctant to join groups that are not homogenous, this approach may help more students integrate while obtaining the academic help they need (Zhao et al., 2005). By forming these types of groups, more American students can interact with international students who can also benefit from the cultural education and assistance with coursework.

Universities can help their international student population by forming groups that will aid students in a positive, useful manner. However, there are many other suggestions and ideas that emerge from the literature that can be mutually beneficial to all parties involved. Poyrazli (2007) suggests programs that will help students cope with discrimination, homesickness, and the transition to college life. These will also benefit freshman and first generation students who may need similar help. Also, students who felt they had a supportive campus environment were more pleased with their university experience, regardless of their home nation (Korobova \& Starobin, 2015). This may indicate that having more support systems, even if they are specific to international students, will translate into higher satisfaction rates among all students. Moreover, international students that fully integrated into the academic system were more likely to remain enrolled at their institution (Mamiseishvili, 2012). Since completion rates and persistence are so important to today's colleges and universities, this is an important distinction to note.

Some of the programs suggested for institutions may not be immediately feasible due to budgetary and staffing concerns. However, there are many suggestions that can be implemented with little cost or effort. For instance, schools can provide more explicit financial information to students before they arrive in the United States (Telbis et al., 2014). There are many hidden costs that international students may not be aware of. These items that Americans take for granted can become frustrating for 
international students. Therefore, it is suggested that universities take a proactive role in providing international students with a list of potential costs and fees that may not normally be provided to students prior to their arrival in the United States.

Many universities have done an excellent job of providing students with groups where they can find people with similar backgrounds. However, Tas (2013) suggests that the university approach should include groups with a purposeful multicultural theme. These groups should reflect the true diversity of ethnic, racial, and international groups that attend the university. By promoting these types of groups, American and international students can interact and receive the benefits of networking and collaboration that may be missing from groups that are aimed at only one cultural group.

Another suggestion that can aid international students in their transition is to include some of the aforementioned items in introductory orientation programs (Sherry et al., 2010). This could be a school wide orientation program, international students only, or could be run by individual schools or departments. By giving cultural, language, and other pertinent information to students, the university can help students before issues arise. In addition, universities should speak with students to determine what factors contribute most to positive student engagement. When universities provide the necessary information to students and receive feedback concerning their desire to continue, the international student population may feel more comfortable with their academic experience.

\section{CONCLUSION}

International students account for significant spending in the United States, but their influence and benefit go far beyond financial aspects. In fact, American students may benefit greatly from increased international student numbers. As the economy and business world become more globalized and the United States becomes more diverse, it is important for universities to remain competitive and provide an education that truly prepares students for the world around them. The current literature offers many insights into the international student experience, but as the evidence shows, universities, faculty, and groups can do more to improve the educational experience for those from other nations. Since American students benefit greatly from the presence of international students, it will pay dividends to continue research in this area. As universities struggle financially, the international student demographic can help to alleviate some of these issues while also improving the education for American students and building bridges between different cultures, economies, and nations. In the future, researchers and universities should examine current English language services offered to international 
students to determine if these programs are being implemented effectively and if students are properly accessing the services offered to them. Finally, individual colleges and departments should look at their individual population to determine how to be most helpful to their international students. While campus wide initiatives may not be possible for all universities, individual departments may be able to use the current research to offer assistance to their international students that will help them to feel welcomed by their department, peers, and faculty.

\section{REFERENCES}

Burdett, J., \& Crossman, J. (2012). Engaging international students. Quality $\begin{array}{llcc}\text { Assurance in } & \text { Education, 20(3), } & \text { 207-222. } \\ \text { http://doi.org/http://dx.doi.org/10.1108/09684881211240286 } & \end{array}$

Curtin, N., Stewart, A. J., \& Ostrove, J. M. (2013). Fostering academic self-concept advisor support and sense of belonging among international and domestic graduate students. American Educational Research Journal, 50(1), 108137. http://doi.org/10.3102/0002831212446662

de Araujo, A. A. (2011). Adjustment issues of international students enrolled in American colleges and universities: A review of the literature. Higher Education Studies, 1(1), 2-8.

Feng, B., \& Feng, H. (2013). Examining cultural similarities and differences in responses to advice: a comparison of American and Chinese college students. Communication Research, 40(5), 623-644. http://doi.org/10.1177/0093650211433826

Gardner, S. K. (2013). The challenges of first-generation doctoral students. New
Directions for Higher Education, 2013(163), 43-54. http://doi.org/10.1002/he.20064

Grayson, J. P. (2008). The experiences and outcomes of domestic and international students at four Canadian universities. Higher Education Research \& Development, 27(3), 215-230. http://doi.org/10.1080/07294360802183788

Habib, L., Johannesen, M., \& Øgrim, L. (2014). Experiences and challenges of international students in technology-rich learning environments. Journal of Educational Technology \& Society, 17(2), 196-206.

Hwang, B. J., Bennett, R., \& Beauchemin, J. (2014). International students' utilization of counseling services. College Student Journal, 48(3), 347354.

Korobova, N., \& Starobin, S. S. (2015). A comparative study of student engagement, satisfaction, and academic success among international and American students. Journal of International Students, 5(1), 72-85.

Lin, S.-Y., \& Scherz, S. D. (2014). Challenges facing Asian international graduate students in the US: Pedagogical considerations in higher education. Journal of International Students, 4(1), 16-33.

Luo, J., \& Jamieson-Drake, D. (2013). Examining the educational benefits of 
interacting with international students. Journal of International Students, 3(2), 85-101.

Mamiseishvili, K. (2012). International student persistence in U.S. postsecondary institutions. Higher Education, 64(1), 1+.

Mitchell, S. L., Greenwood, A. K., \& Guglielmi, M. C. (2007). Utilization of counseling services: Comparing international and U.S. college students. Journal of College Counseling, 10(2), 117-129.

Poyrazli, S., \& Lopez, M. D. (2007). An exploratory study of perceived discrimination and homesickness: A comparison of international students and American students. Journal of Psychology, 141(3), 263-280.

Rodgers, L. S., \& Tennison, L. R. (2009). A preliminary assessment of adjustment disorder among first-year college students. Archives of Psychiatric Nursing, 23(3), 220-230. http://doi.org/10.1016/j.apnu.2008.05.007

Sherry, M., Thomas, P., \& Chui, W. H. (2010). International students: A vulnerable student population. Higher Education, 60(1), 33-46. http://doi.org/http://dx.doi.org/10.1007/s10734-009-9284-z

Telbis, N. M., Helgeson, L., \& Kingsbury, C. (2014). International students’ confidence and academic success. Journal of International Students, 4(4), 330-341.

Zhao, C.-M., Kuh, G. D., \& Carini, R. M. (2005). A comparison of international student and American student engagement in effective educational practices. The Journal of Higher Education, 76(2), 209-231. http://doi.org/10.1353/jhe.2005.0018

CODY J. PERRY, is a graduate student and teaching assistant, currently pursuing a $\mathrm{PhD}$ in Curriculum Studies at the University of Wyoming. Email: cperry12@uwyo.edu 